\title{
Histopathological findings in elderly patients
}

\begin{abstract}
Authors
Priscylla Aparecida Vieira do Carmo ${ }^{1}$

Gianna Mastroianni Kirsztajn²

Wander Barros do Carmo ${ }^{1}$

Marcello Fabiano

Franco $^{3}$

Marcus Gomes

Bastos $^{4}$

IIMEPEN Foundation

2Discipline of

Nephrology, Department

of Medicine of the

Escola Paulista of

Universidade Federal

de São Paulo (UNIFESP)

EPM)

${ }^{3}$ Department of

Pathology of the

UNIFESP/EPM

${ }^{4}$ Discipline of

Nephrology of the

Medical School of the

Universidade Federal de

Juiz de Fora
\end{abstract}

Submitted on: 06/22/2010

Accepted on: 07/09/2010

Corresponding author:

Priscylla Aparecida Vieira do

Carmo

R. Delfim Moreira, 252, ap.

503. Centro - Juiz de Fora -

Mina Gerais

CEP: 36010-570

E-mail:pvcarmo@gmail.

com

We declare no conflict of interest.

\section{Abstract}

Introduction: The elderly population has significantly increased worldwide and recent studies have evidenced a 10-year increase in Brazilian life expectancy. Similarly to other comorbidities, glomerular diseases are also observed in the elderly, and, in that age group, kidney biopsy emerges as a fundamental diagnostic tool to help disease management, preventing unnecessary therapies. Objective: To establish the frequency of histological diagnoses in the elderly undergoing kidney biopsy, with an emphasis on glomerulopathies (GPs), at two Brazilian universities. Methods: Retrospective assessment of kidney biopsy reports of the Department of Pathology of UNIFESP (patients aged 60 years or above, from 01/01/1996 to $12 / 31 / 2003$ ) and of the outpatient clinic of GPs of NIEPEN. The studies of transplanted kidneys and nephrectomies were excluded. The following data were analyzed: age; sex; clinical syndrome at presentation; and histological diagnosis (light microscopy and immunofluorescence). Nephropathies were classified as primary GPs, secondary kidney diseases, nonglomerular diseases, and others. Results: One hundred and thirteen biopsies were assessed, the mean age of patients was $66.0 \pm 6.0$ years, and the male sex prevailed $(54.8 \%)$. The most common clinical presentation was nephrotic syndrome $(32.7 \%)$, followed by acute and chronic kidney failure $(18.6 \%$, each). Glomerular diseases were as follows: membranous nephropathy (MN), 15\%; hypertensive nephrosclerosis, $11.5 \%$; focal segmental glomerulosclerosis and vasculitis/crescentic GN, 9.7\% each; amyloidosis, chronic glomerulonephritis, and minimal change disease, $7.1 \%$ each; diffuse proliferative
GN, 4.4\%; IgA nephropathy and lupus nephritis, $2.7 \%$ each. Primary GPs predominated $(45.2 \%)$ as compared with other nephropathies. Conclusion: Nephrotic syndrome was the major indication for kidney biopsy. Regarding the kidney histological diagnoses, glomerular diseases predominated, in particular $\mathrm{MN}$ and hypertensive nephrosclerosis, findings compatible with previous studies in the area, but rarely assessed among us. It is clear that the diversity of diagnoses and differentiated treatments justify kidney biopsy for decision making in that group of patients.

Keywords: aged, biopsy, glomerulonephritis, nephrotic syndrome, chronic kidney failure.

[J Bras Nefrol 2010;32(3):282-287]@Elsevier Editora Ltda.

\section{INTRODUCTION}

In general, the elderly population has significantly increased. This results from technological innovation and advances in quality of life, as well as from the decline in the fecundity and mortality rates in each year. These factors contribute to the aging profile our country has shown lately. ${ }^{1}$

According to the Brazilian Institute of Geography and Statistics (IBGE), the aging index indicates changes in the Brazilian population longevity. According to the 2008 demographic census, for every 100 children aged 0 to 14 years, there were 24.7 elderly aged 65 years or above, 
and the projection for 2050 is an increase to 172.7 elderly. ${ }^{1}$ Another evidence of the population aging is the increase in life expectancy of Brazilians, currently of 72.78 years. That mean should continue to increase and, by 2050, life expectancy is expected to have increased to 81.29 years, equaling that of countries with high human development index, such as Iceland (81.8 years) and Japan (82.6). ${ }^{1}$

The use of new instruments and technology appears as a perspective for approaching that age group. Thus, it is increasingly clear that advanced age by itself is no longer an obstacle to medical investigations or interventions, considering that invasive diagnostic procedures and even therapeutic tools have become safer. Nephrology reflects that reality in the increasing number of elderly patients undergoing renal replacement therapies and in the higher demand for kidney transplantation. ${ }^{2}$

Regarding glomerular disease, the histopathological assessment of renal tissue is the investigation method capable of establishing the definitive diagnosis. In addition, the information obtained by use of kidney biopsies does not only identify the specific diagnosis, but also provides a prognostic index, helping in deciding the therapeutic management in each case. ${ }^{3,4}$

The incidence of glomerulopathies in the elderly has greatly varied in the different series analyzed, from almost null to up to $25 \% .^{5}$ The diagnosis of glomerular disease may be underestimated in the elderly, because its symptoms can be attributed to asymptomatic systemic diseases and urinary abnormalities can be diagnosed as urinary tract diseases, such as prostatitis. In addition, in the presence of comorbidities, many professionals still maintain a conservative attitude towards invasive diagnostic procedures and therapeutic interventions in that population, because of the risk of complications. ${ }^{6}$

Considering that the procedure is safe and that glomerular diseases, even in that age group, can be treated, or, on the contrary, that unnecessary immunosuppression can be prevented, kidney biopsy appears as an unquestionable diagnostic tool for the elderly. ${ }^{7,8}$

This study aimed at assessing the most frequent clinical presentation and histopathological diagnoses in the elderly population suspected of having glomerular disease at the Federal University of São Paulo/ Paulista Medical School (UNIFESP/EPM) and outpatient clinic of glomerulopathies of the Interdisciplinary Nucleus of Education and Research in Nephrology (NIEPEN) of the University of Juiz de Fora, in the state of Minas Gerais.

\section{Methods}

A retrospective analysis was conducted with 92 kidney biopsy reports from elderly patients of the Department of Pathology of UNIFESP, from 01/01/1996 to 12/31/2003, and with 21 kidney biopsy reports from the outpatient clinic of glomerulopathies of NIEPEN, from 01/01/1996 to 12/31/2009.

Individuals aged 60 years or above were arbitrarily considered elderly. For each case, the following data were extracted from the biopsy reports and analyzed: age; sex; clinical syndrome at presentation; and histological diagnosis. Biopsies from transplanted kidneys and nephrectomies were not included in the study.

According to the description in the requisition form for kidney biopsy completed by the assistant nephrologist, the clinical syndromes at presentation were divided as follows: nephrotic syndrome; nephritic syndrome; urinary abnormalities; acute kidney failure (AKF); and chronic kidney failure.

Histological diagnosis was established by use of light microscopy and immunofluorescence. The nephropathies were classified as follows: primary glomerulopathies; secondary kidney diseases; nonglomerular diseases; and others. Primary glomerulopathies referred to conditions in which the kidneys were the only organs affected, while in secondary kidney diseases, there was evidence of associated systemic disease.

\section{Results}

One hundred and thirteen kidney biopsies of patients aged 60 years or above were assessed. Their mean age was $66.0 \pm 6.0$ years. The male sex prevailed $(54.8 \%)$. The primary glomerulopathies were the most frequent, accounting for $45.2 \%$ of the kidney biopsies, followed by secondary kidney diseases, accounting for $35.4 \%$ of the sample. Table 1 shows the classification of the glomerulopathies and their frequencies.

Nephrotic syndrome was the most common clinical presentation, indicating kidney biopsy in $32.7 \%$ of the cases. Acute and chronic kidney failure accounted for kidney biopsy indication in $18.6 \%$ of the patients. Asymptomatic urinary abnormalities affected $16.8 \%$ of the elderly at presentation. In $10.6 \%$ of the biopsy reports, there was no description of the syndrome responsible for kidney biopsy indication (Table 2).

Figures 1 and 2 show the most frequent diagnoses in cases of nephrotic syndrome and acute kidney failure, with predominance of membranous nephropathy and vasculitis, respectively.

The most common histopathological findings in the elderly are shown in Table 3. Membranous 
nephropathy was the most frequent disease, observed in $15 \%$ of kidney biopsies. Hypertensive nephrosclerosis was the second most common finding in the elderly, totaling $11.5 \%$ of all biopsies. Vasculitis and focal segmental glomerulosclerosis (FSGS) were equally frequent and identified in $9.7 \%$ of the cases. Amyloidosis, minimal change disease, and chronic glomerulonephritis accounted for $7.1 \%$ of the glomerular diseases in the elderly.

Immunofluorescence findings were positive in $30 \%$ of the cases and negative in $36 \%$. In the remaining biopsies (34\%), the specimen was insufficient for analysis (Figure 3).

Of the primary glomerulopathies, membranous nephropathy was the most common, followed by FSGS and minimal change disease, accounting for $33.3 \%, 21.6 \%$, and $15.7 \%$ of the cases, respectively (Figure 4).

Figure 5 shows the most frequent secondary diseases. The major cause of secondary kidney disease in the elderly was hypertensive nephrosclerosis $(32.5 \%)$, followed by vasculitis and amyloidosis, accounting for $27.5 \%$ and $20.0 \%$, respectively. Only three cases of lupus nephritis were observed.

\section{Discussion}

Despite the limitations of the retrospective approa$\mathrm{ch}$, this study has epidemiological importance in face of the scarcity of similar studies, mainly in Brazil. Through review of kidney biopsy reports from two Brazilian regions, the spectrum of glomerular diseases was assessed, as were the major indications for kidney biopsy in the population over the age of 60 years.

In our study population, the male sex predominated slightly, in accordance with other studies assessing populations of the same age..$^{9,10,11}$ On the other hand, assessments of patients over the age of 80 years found a higher frequency of women, possibly because of their longer life expectancy. ${ }^{12,13}$

Similarly to that found in the younger population, nephrotic syndrome is a very common and unquestionable condition requiring kidney biopsy. ${ }^{14}$ In our study, nephrotic syndrome was the major indication for kidney biopsy, followed by acute kidney failure, a finding consistent with those of other studies with the same age bracket. ${ }^{15,16,10,11,17}$ In a recent publication, the Spanish Registry of Glomerulonephrites has also found a similar profile, but with an even higher percentage of AKF than the one here reported. Despite the unfavorable evidence against kidney biopsy in AKF in the elderly, because of the high clinical-pathological correlation, ${ }^{18,19}$ Haas has reported that, in one third of the elderly, the histopathological diagnosis differed from clinical suspicion. ${ }^{15}$ In our study, the major

\section{Table 1 Demographic and histological data}

\begin{tabular}{lc} 
Age (years) & $66 \pm 6$ \\
Sex (\%) & \\
Female & 45.1 \\
Male & 54.8 \\
Histological classification (\%) & \\
Primary glomerulopathies & 45.2 \\
Secondary glomerulopathies & 35.4 \\
Nonglomerular kidney diseases & 9.7 \\
Others & 9.7 \\
\hline
\end{tabular}

Table 2 DISTRIBUTION OF THE CLINICAL SYNDROMES

Nephrotic syndrome 32.7

Acute kidney failure 18.6

Chronic kidney failure 18.6

Asymptomatic urinary

abnormalities

16.8

Ignored

10.6

Nephritic syndrome

cause of AKF was vasculitis (31.8\% of AKF causes), followed by "acute diffuse glomerulonephritis" and acute tubular necrosis (ATN), both with $18.2 \%$ of the AKF causes. Moutzouris et al., ${ }^{13}$ assessing a population over the age of 80 years with AKF, reported ATN in only $5 \%$ of the cases, evidencing excellent clinical screening for kidney biopsy by the assistant nephrologist.

Membranous nephropathy is known to be the most common histological pattern in the elderly, and its frequency varies depending on the population studied and the indications for biopsy of each service..$^{2,67,9,20,21}$ In our study, membranous nephropathy was also the most frequent glomerular disease, corresponding to $15 \%$ of the sample, a finding similar to that of a recent survey of the Paulista Registry of Glomerulopathies, whose percentage was $13.1 \% .^{22}$

In our study, hypertensive nephrosclerosis was the second most common histological pattern, a finding justified by the high prevalence of arterial hypertension in that age group, which can reach up to $50 \% .^{23}$ However, hypertensive nephrosclerosis can be a 
Figure 1. Frequency of glomerulopathies in nephrotic syndrome.

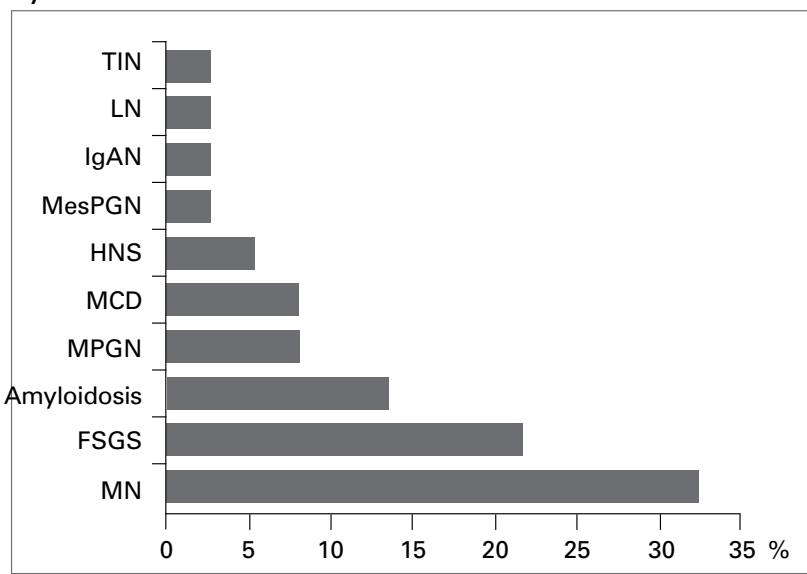

MN: Membranous nephropathy; FSGS: focal segmental glomerulosclerosis; MPGN: membranoproliferative glomerulonephritis; MCD: Minimal change disease; HNS: Hypertensive nephrosclerosis; MesPGN: mesangioproliferative glomeruIonephritis; IgAN: IgA nephropathy; LN: lupus nephritis; TIN: tubulointerstitial nephritis

Figure 2. Frequency of glomerulopathies in acute kidney failure.

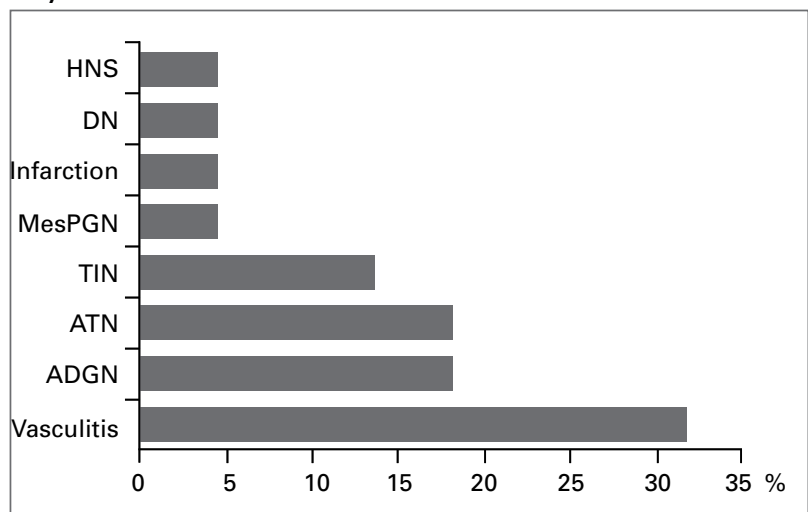

HNS: Hypertensive nephrosclerosis; DN: Diabetic nephropathy; MesPGN: mesangioproliferative glomerulonephritis; TIN: tubulointerstitial nephritis; ATN: acute tubular necrosis; ADGN: acute diffuse glomerulonephritis.

\section{Table 3 DISTRIBUTION OF LIGHT MICROSCOPY FINDINGS}

Histopathological diagnoses

n $\quad \%$

Membranous nephropathy

Hypertensive nephrosclerosis

$13 \quad 11.5$

Focal segmental glomerulosclerosis

Vasculitis

Amyloidosis

Chronic glomerulonephritis

Minimal change disease

Acute diffuse glomerulonephritis

IgA nephropathy

Lupus nephritis

Others

Total difficult diagnosis, since nephrosclerosis is a histological lesion also observed in patients with ischemic nephropathy secondary to vascular kidney disease. ${ }^{24}$ In addition, it is a common condition in the so called "terminal" kidney disease of different etiologies and can result from aging. ${ }^{25}$

Figure 3 - Distribution of immunofluorescence findings.

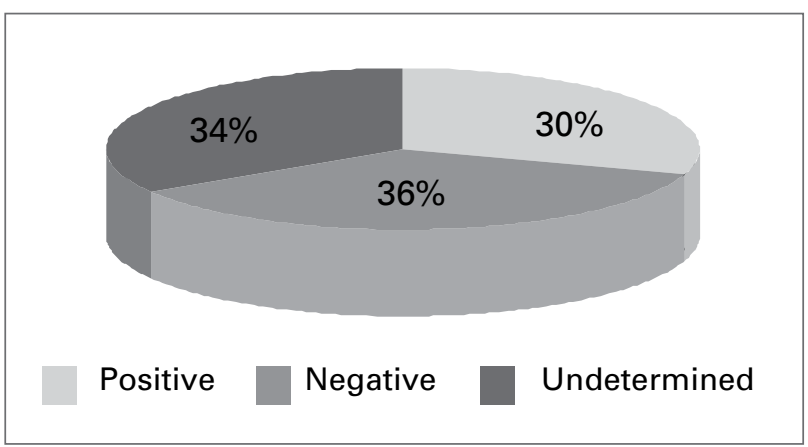

Figure 4. Frequency of primary glomerulopathies ( $n=51)$.

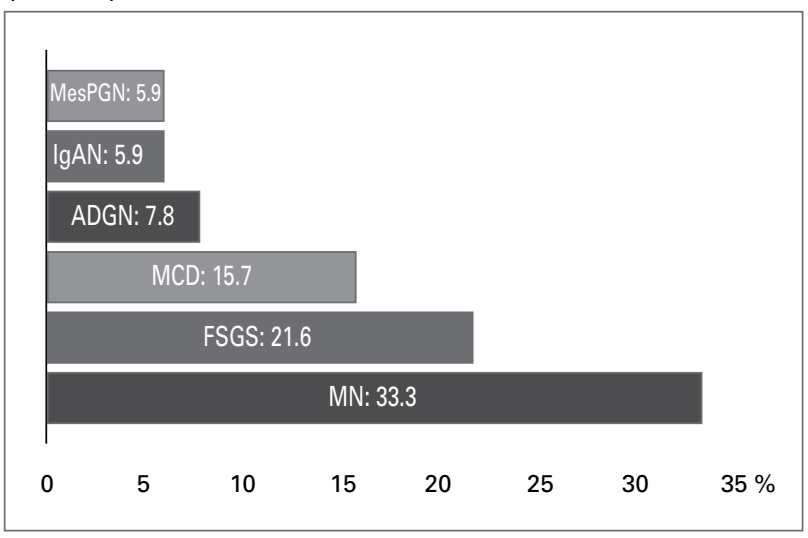

MesPGN: Mesangioproliferative glomerulonephritis; IgAN: IgA nephropathy; ADGN: acute diffuse glomerulonephritis; MCD: Minimal change disease; FSGS: Focal segmental glomerulosclerosis; MN: Membranous nephropathy.

Figure 5. Frequency of secondary kidney diseases $(n=40)$.

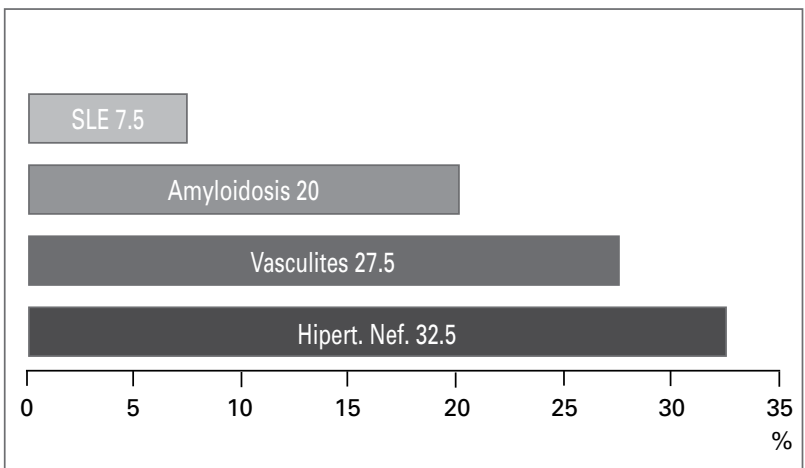


Vasculites are very frequent in the elderly population. Furci et al. ${ }^{26}$ have reported a $10 \%$ prevalence, which is four times greater than that in the adult. In our study, we found a similar percentage $(9.7 \%$ of the cases), which was also observed in other studies. ${ }^{2,6,15}$

Although considered rare in the elderly population, not exceeding 4\%, FSGS has also reached almost $10 \%$ of the elderly biopsies in our study, maybe because that is the most frequent glomerular disease in both regions here assessed.22,27

Contrary to most studies showing a high percentage of amyloidosis, in ours, only $7 \%$ of the biopsy reports had that diagnosis, despite the high number of nephrotic elderly (32.7\% of the population). A Korean series has also diagnosed a reduced number of cases of amyloidosis in the elderly, not exceeding $6 \% .^{6}$

Aiming at assessing the usefulness of the kidney biopsy in that group, we observed that in $53.5 \%$ of our cases a therapeutic intervention would be necessary. Nair et al. ${ }^{12}$, studying a population over the age of 80 years, have reported $40 \%$ of diagnoses with consequent therapeutic indication. It is worth emphasizing that the decision of initiating or not an intervention in that group of patients should be very cautious, always considering the comorbidities that limit the choice of more aggressive therapies. On the other hand, even for patients whose histopathological diagnosis can not alter management, the information about prognosis can be fundamental to prevent unnecessary and even deleterious empirical treatments.

In conclusion, kidney biopsy in the elderly provides important information about diagnosis and prognosis in different clinical presentations, mainly when investigating nephrotic syndrome and acute kidney failure. In addition, advanced age by itself should not induce reluctance to perform kidney biopsy. Considering the greater tendency to longevity, further studies in this area should be encouraged, aiming at guiding not only nephrologists, but also internists, so that morbidity and mortality in the elderly can be prevented, and treatment become more effective.

\section{References}

1. Ministério do Planejamento, Orçamento e Gestão. Instituto Brasileiro de Geografia e Estatística - IBGE. Projeção da população do Brasil por sexo e idade 19802050 Revisão 2008. Disponível em: [http://www.ibge. gov.br/home/estatistica/populacao/ projecao_da_populacao/2008/projecao.pdf] Acesso em: 03 de novembro de 2009.

2. Woronik V, Oliveira MB, Malafronte P, Barros RT. Glomerulopatias em pacientes idosos: aspectos clínicos e histopatológicos. J Bras Nefrol 2003; 25:172-8.
3. Freitas MJR, Ribeiro RT. Aspectos clínico-patológicos de pacientes submetidos à biopsia renal. Rev Paraense Med 2006; 20:15-22.

4. Llanes OB, Abreu JF, Bomboust IP, Cura RC Salazarte AV. La biopsia renal en el diagnóstico de las glomerulopatías. Rev Cuba Med 2002; 41:87-92.

5. Prakash J, Saxena RK, Sharma OP, Usha. Spectrum of renal diseases in the elderly: single center experience from a developing country. Int Urol Nephrol 2001; 33:227-33.

6. Shin JH, Pyo H-J, Kwon YJ et al. Renal biopsy in elderly patients: clinicopathological correlation in 117 Korean patients. Clin Nephrol 2001; 56:19-26.

7. Davison AM. Renal disease in the elderly. Nephron 1998; 80:6-16.

8. Kohli HS, Jairam A, Bhat A et al. Safety of kidney biopsy in elderly: a prospective study. Int Urol Nephrol 2006; 38:815-20.

9. Davison AM, Johnston PA. Glomerulonephritis in the elderly. Nephrol Dial Transplant 1996; 11:34-7.

10. Rivera F, Lopez Gomez JM, Perez Garcia R. Clinicopathologic correlations of renal pathology in Spain. Kidney Int 2004; 66:898-904.

11. Schena FP. Survey of the Italian Registry of Renal Biopsies. Frequency of the renal diseases for 7 consecutive years. The Italian Group of Renal Immunopathology. Nephrol Dial Transplant 1997; 12:418-26.

12. Nair R, Bell JM, Walker PD. Renal biopsy in patients aged 80 years and older. Am J Kidney Dis 2004; 44:618-26

13. Moutzouris DA, Herlitz L, Appel GB et al. Renal biopsy in the very elderly. Clin J Am Soc Nephrol 2009; 4:1073-82.

14. Bolton KN. Nephrotic syndrome in the aged. In: Cameron JS, Glassock RJ, eds. The Nephrotic Syndrome. New York: Marcel Dekker, 1998; p. 523-54.

15. Haas M, Spargo BH, Wit EJ, Meehan SM. Etiologies and outcome of acute renal insufficiency in older adults: A renal biopsy study of 259 cases. Am J Kidney Dis 2000; 35:433-47.

16. Ferro G, Dattolo P, Nigrelli S, Michelassi S, Pizzarelli F. Clinical pathological correlates of renal biopsy in elderly patients. Clin Nephrol 2006; 65:243-7.

17. Covic A, Schiller A, Volovat C et al. Epidemiology of renal disease in Romania: a 10-year review of two regional renal biopsy databases. Nephrol Dial Transplant 2006; 21:419-24.

18. Macias-Nunes JF, Lopez-Novoa JM, MartinezMaldonado M. Acute renal failure in the aged. Semin Nephrol 1996; 16:330-8.

19. Liano F, Pascual J. Epidemiology of acute renal failure: a prospective, multicenter, community-based study. Madrid Acute Renal Failure Study Group. Kidney Int 1996; 50:811-8.

20. Rivera F, López-Gómez JM, Pérez-García R. Papel del Registro de Glomerulonefritis de la Sociedad Espanola de Nefrologia: pasado, presente y futuro. Nefrologia 2000; 20:41-4.

21. Hanko JB, Mullan RN, O’Rourke DM, McNamee PT, Maxwell AP, Courtney AE. The changing pattern of adult primary glomerular disease. Nephrol Dial Transplant 2009; 24:3050-4.6. 
22. Polito MG, Moura LA, Kirsztajn GM. An overview on frequency of renal biopsy diagnosis in Brazil: clinical and pathological patterns based on 9617 native kidney biopsies. Nephrol Dial Transplant 2010; 25:490-6.

23. Zaitune MPA, Barros MBA, César CLG, Carandina L, Goldbaum M. Hipertensão arterial em idosos: prevalência, fatores associados e práticas de controle no município de Campinas, São Paulo, Brasil. Cad Saúde Pública, Rio de Janeiro, 2006; 22:285-94.

24. Zucchelli P, Zuccala A. Ischemic nephropathy in the elderly. Contrib Nephrol 1993; 104:13-24.
25. Lindeman RD. Renal physiology and pathophysiology of aging. Contrib Nephrol 1993; 104:1-12.

26. Furci L, Baraldi A, Medici G, Maccari D, Lusvarghi E. Nephropathies in the elderly. In: Sessa A, Meroni M, Battini G Eds. Glomerulonephritis in the elderly. Contrib Nephrol 1993; 105:157-60.

27. Carmo PAV, Carmo WB, Bastos MG, Andrade LCF. Estudos das doenças glomerulares na Zona da Mata Mineira. J Bras Nefrol 2008; 30:15-21. 